\title{
Material hibrido organiko-ez-organiko fluoreszenteak aplikazio optikoetarako
}

(Fluorescent organic-inorganic hybrid materials for optical applications)

\author{
Rebeca Sola-Llano \\ Euskal Herriko Unibertsitatea (UPV/EHU) \\ rebeca.sola@ehu.eus
}

DOI: $10.1387 /$ ekaia.17823

Laburpena: Aplikazio optikoetarako material hibrido egokiak aurkitu nahian, koloratzaile desberdinak MgAPO-11 aluminofosfato ez-organikoan kapsulatu dira. Material zeolitiko honek AEL egitura dauka, dimentsio bakarreko nanokanal eliptiko oso estuak dituena, 6,5 ×4 $\AA^{2}$-ko diametrodunak; beraz, erabiliko diren koloratzaileen neurri molekularra kontuan izanik, oso estu kapsulatuak geratuko dira. Hori dela eta, koloratzailea sintesi-nahastera gehitzea beharrezkoa da kapsulatuak gera daitezen. Sintesi-metodo horren bidez koloratzaileak modu oso ordenatuan AELaren kanaletan harrapatzen dira $10 \mu \mathrm{m}$ baino gehiagoko luzeradun partikuletan, euren ardatz molekular luzearekin kanalekiko paralelo, eta koloratzaile molekulen agregazioa saihesten da. Alde batetik, akridina (AC) eta pironina Y (PY) kromoforoak material zeolitikoan batera kapsulatu direnean, material hibrido oso fluoreszentea lortu da. Gainera, bi kromoforoen trantsizio-momentu dipolarrak bata bestearekiko perpendikularrak direnez, eta haien artean FRET energia-transferentzia eraginkorra gertatzen denez, partikulen emisio fluoreszentearen kolore-aldaketa ikus daiteke (zianetik berdera) materiala argi ultramorearekin kitzikatu ostean, bide optikoan detekzioaren aurretik koka daitezkeen polarizatzaileen norabidearen arabera. Azkenik, LDS 722 koloratzailea sartu da euskarri ez-organikoan eta emaitza gisa espektro elektromagnetikoaren alde gorrian igortzen duen material hibrido oso fluoreszentea eskuratu da. Bere etekin kuantikoa koloratzaileak disoluzio urtsuan azaltzen duena baino 50 bat aldiz altuagoa da, eta gainera, LDS 722ak optika ez-linealerako propietate intrintsekoak dituenez, eta partikuletan molekulek duten ordenamendu maila altua dela eta, material hibrido egokia lortu da bigarren harmonikoaren sorkuntzarako (SHG).

Hitz gakoak: 1D-kanaldun aluminofosfatoa, koloratzaile fluoreszenteak, kolore-aldaketa, FRET, optika ez-lineala.

Abstract: In the search of new hybrid materials suitable for optical applications, different dyes were occluded into the MgAPO-11 inorganic aluminophosphate. This ze- 
olitic material has an AEL structure type containing very narrow one-dimensional nanochannels with a diameter of $6.5 \times 4 \AA^{2}$. Thus, taking into account the molecular dimensions of the dyes to be encapsulated herein, they will get tightly occluded into the inorganic host structure. For this reason, dyes must be added to the initial synthesis gel in order to success in the incorporation of those chromophores into the material. With this synthetic approach, chromophores are encapsulated in a highly ordered arrangement into the nanochannels of the big particles of the AEL structure, exceeding $10 \mu \mathrm{m}$ in length, forcing the dye molecules to place with their long molecular axis parallel with respect to the channels' direction. Furthermore, the narrow size of the channels avoids dye aggregation into the aluminophosphate. Firstly, acridine (AC) and pyronin Y (PY) dyes were simultaneously encapsulated into the inorganic zeolitic host obtaining a highly fluorescent hybrid material. Moreover, as the transition dipolar moments of the two dyes are perpendicular to each other, and since an efficient FRET energy transfer takes place between them, a fluorescence emission colour-switching of the particles is seen under UV excitation light (from cyan to green) depending on the direction of the polarizers placed before detection. Finally, a different dye was occluded into the MgAPO-11, the LDS 722 dye, and as a result a highly fluorescent hybrid material emitting in the red edge of the electromagnetic spectrum was achieved. Its fluorescence quantum yield is around 50 times higher than that recorded for the dye in aqueous solution and, given that the LDS 722 shows intrinsic Non-Linear Optical properties, together with the fact that the chromophore molecules show a ordered arrangement into the system, an appropriate hybrid material for Second Harmonic Generation $(\mathrm{SHG})$ has been obtained.

Keywords: 1D-channeled aluminophosphate, fluorescent dyes, colour-switching, FRET, non-linear optics.

\section{SARRERA}

Material hibrido organiko-ez-organikoek eskala nanometrikoan osagai organiko eta ez-organikoak bateratzen dituzte, eta mota anitzekoak izan daitezke; adibidez koordinazio-polimero kristalinoak, sol-gel konposatu amorfoak, edo angstrom $\left(1 \AA=10^{-10} \mathrm{~m}\right)$ gutxi batzuetako unitate organiko eta ez-organikoak dituen edozein sistema molekular [1]. Horiek oso interesgarriak dira gaur egun, aplikazio teknologiko ugaritan izan diren aurrerapenak direla eta, propietate bereziak azaltzen dituzten materialak behar direlako eta askotan ohiko materialek ez dutelako horrelako ezaugarri apartekorik $[1,2]$. Testuinguru horretan, material hibridoek konposatu organiko eta ez-organikoen propietateak sistema bakarrean eta modu eraginkorrean batera biltzeko aukera ematen dute, non azken ezaugarriak ez diren bakarrik bakarkako unitateen propietateen batura: propietate berriak edo hobetuak ere ager daitezke sinergia-efektua dela eta $[1,3]$.

Dena den, antzinatik ezagutzen dira material berriak lortzeko zenbait estrategia. Esate baterako, buztinetan oinarritzen diren konposatu hibridoak historikoki erabili izan dira, adibidez, garbiketa prozesuetan (gernua- 
rekin nahasiak) edo margoetan (koloratzaile organikoekin nahasiak) [3-5]. Azken horren adibide oso ezaguna da antzinako «Maya Blue» pigmentua, buztin ez-organikoak koloratzaile organikoari eskaintzen dion babesa dela eta, oso iraunkorra dena [6].

Horrekin jarraituz, esan beharra dago koloratzaileen barneratzea sistema nanoegituratu ordenatuetan estrategia egokia dela propietate optiko, kimiko zein elektriko interesgarriak dituzten material berri eta baliagarriak lortzeko. Ildo horretan, dimentsio bakarreko zeolitak eta mikroporoak dituzten zeotipoak oso interesgarriak dira material anfitrioi gisa erabiltzeko, duten egituraren izaera irekia eta ondo definituriko barne-kanalak direla eta [7-9]. Koloratzaileak egitura horietan sartzean lortzen diren material hibridoek barne-antolaketa maila oso altua erakusten dute, non molekula fotoaktiboak orientazio jakin batean lerrokatzen diren, euskarri ez-organikoak ezartzen dituen murrizketa geometrikoak direla medio. Ondorioz, koloratzaile-molekulen distribuzio oso monomerikoak, eta anisotropoak eskuratu daitezke [10]. Hau da, koloratzaile-molekulak bata bestetik isolatuak egotea lor daiteke, eta horrela, haien artean gerta daitezkeen elkarrekintza negatiboak saihestu, eta makroskopikoki ordenamendu maila altua eskuratu.

Izan ere, aplikazio optikoetarako baliagarriak diren materialek koloratzaile-kontzentrazio oso altuak behar dituzte, eta baldintza horietan koloratzaile asko agregatu egiten dira, ez ditugu distribuzio monomeriko batean aurkitzen, eta haien propietate fotofisikoak kaltetzen dira [10,11]. Beraz, erabakigarria da euskarri ez-organikoan koloratzaileen monomeroak bakarrik sartzea, molekulen arteko elkartzeko joera saihesteko, eta horrela, material fluoreszenteagoak lor daitezke. Agregatuei dagokienez, bi motatakoak aurki ditzakegu: $\mathrm{H}$ eta $\mathrm{J}$ agregatuak. $\mathrm{H}$ agregatuetan molekula organikoak plano paraleloetan kokatzen dira, eta absortzio-espektroan antzeman daitezke bandak ematen dituztelako espektro elektromagnetikoaren eremu energetikoago batean monomeroekin konparatuz (1. irudia). Horretaz gain, ez dira fluoreszenteak. Bestalde, J agregatuek, non molekula organikoak bata bestearen atzean gertu lerrokatzen diren, gorriranzko absortzio- eta emisio-bandak ematen dituzte monomeroekin konparatuz (1. irudia) [12]. Dena den, bi agregatu motek materialaren fluoreszentzia itzal dezakete $[13,14]$; beraz, lan honetan dimentsio bakarreko nanokanal oso estuak dituen aluminofosfato bat aukeratu da koloratzaile fluoreszenteen anfitrioi gisa erabiltzeko eta agregatuen formazioa ekiditeko.

Aukeratutako aluminofosfatoa MgAPO-11 da, AEL deritzon egitura duena, eta magnesioarekin dopatua dagoena fluoroforo kationikoak barne hartu ditzan. Beste lan batzuetan egiaztatu zen material honen nanokanal estuetan, 6,5 ×4 $\AA^{2}$-ko diametrodunak hain zuzen [15], ezinezkoa zela koloratzaile-molekulen agregaturik aurkitzea (2. irudia) [10]. Alde batetik, kanalen dimentsioak koloratzaileen egitura molekularraren neurrie- 


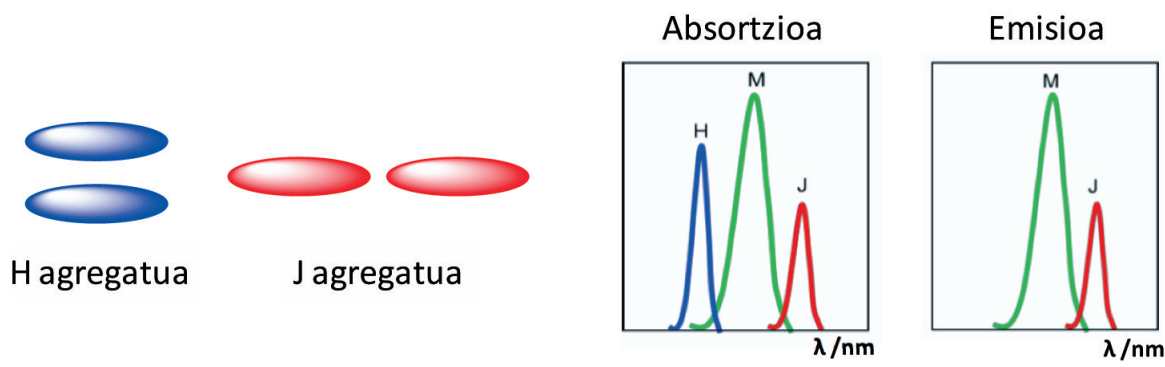

1. irudia. (Ezkerraldean) $\mathrm{H}$ eta $\mathrm{J}$ agregatuetan molekulek duten antolaketa eskematikoki adierazita. (Eskuinaldean) Agregatu mota horien absortzio- eta emisiobanden (izatekotan) kokapena monomeroen bandekin konparatuz, berriro ere eskematikoki irudikatuta.

tara egokitzen dira eta, beraz, $\mathrm{H}$ agregatuak agertzea ezinezkoa litzateke; beste aldetik, kanalen topologia berezia dela eta, poltsiko antzeko barrunbeak dituztenak (2. irudia), J agregatuak ere saihestuko lirateke [10]. Hala ere, kanalen dimentsioak hain estuak izanik, ezin dira koloratzaile organikoak euskarri ez-organikora gehitu ohikoak diren sintesi osteko metodoak jarraituz [16-18]; beharrezkoa da fluoroforoak sintesi-nahastera gehitzea materiala eratzen den heinean poroetan harrapaturik gera daitezen. Sintesimetodo honek abantaila nabarmenak aurkezten ditu, hala nola, betetze homogeneoagoa poroen sarreretan buxadurak eragotziz, eta material hibridoa prestatzeko behar den denboraren murrizketa [19].
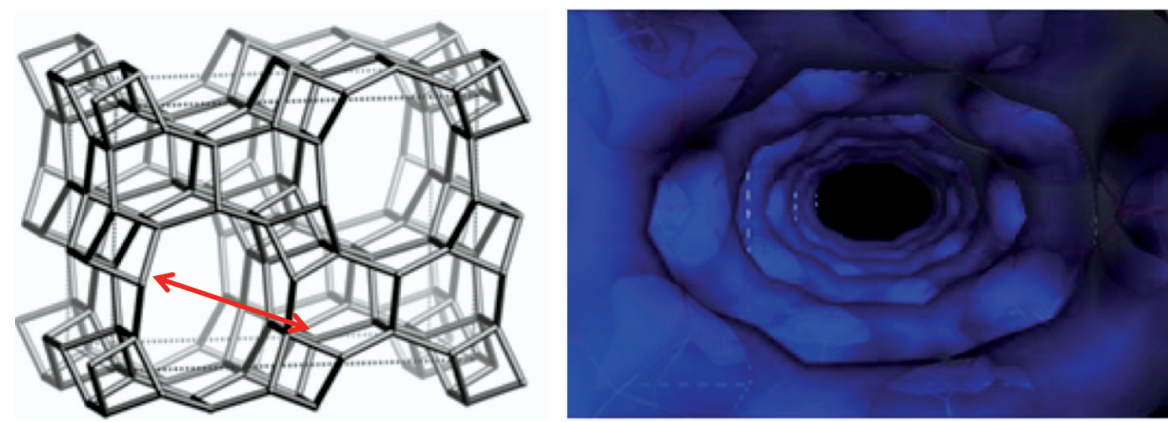

2. irudia. (Ezkerraldean) MgAPO-11, edo AEL, motatako euskarriaren egitura; bere c ardatza kanalen norabidearekiko paraleloa da, geziak adierazten duen moduan [15]. (Eskuinaldean) AEL egituraren kanalen poltsikodun topologia.

Pauso bakarreko sintesi horretan lehenengo saiakerak pironina Y (PY) koloratzailearekin egin ziren, agregazioa aztertzeko sentsore egokia delako [10]. Lan honetan ere PYa erabili da, baina beste koloratzaile batekin 
batera gehitu da sintesi-nahastera, akridinarekin (AC) hain zuzen, aldi berean kapsulatuak gera daitezen. Koloratzaile horiek espektro elektromagnetikoaren eremu desberdinetan argia igortzen dutenez, PYak berdean eta ACak urdinean hain zuzen, igorpen zabala eta intentsua erakusten duen material hibridoa lortzea dugu helburu. Bestalde, espektro elektromagnetikoaren eremu gorrian igortzen duen material bat lortu nahian, LDS 722 hemizianina kapsulatu da egitura ez-organikoan.

\section{MATERIAL HIBRIDOEN SINTESIA}

Aluminofosfatoak prestatzeko metodo ohikoena sintesi hidrotermala da, sol-gel deritzon kimikan oinarritutakoa, nahiz eta beste prozeduren bitartez ere lortu ahal diren [20-22]. Oro har, lan honetan jarraitutako sintesi prozeduran aluminio eta fosforo iturriak diren produktu kimikoak uretan nahasten dira, eta nahastura horri egitura zuzentzen duen konposatu bat ere gehitzen zaio, etilbutilamina (EBA) hain zuzen, dopatzailea izango den magnesioaren gatz batekin batera. Aurretik aipatu den moduan, gure intereseko material hibridoa lortzeko, koloratzaile-molekulak euskarri ez-organikoa hazten den heinean ostatatuta geratu behar dira. Hori dela eta, koloratzailea edo koloratzaileak (kromoforo desberdinak aldi berean kapsulatuak geratzea nahi dugunean) ere sintesi-nahastera gehitu beharra dago. Gero nahaste hori edukiontzi hermetikoetan labera eramaten da, non kristalizazioa gertatuko den. Gure kasuan, lehenengo sintesian AC eta PY koloratzaile fluoreszenteak gehitu dira sintesian, eta bigarren kasuan, berriz, bakarrik LDS 722 kromoforoa (3. irudia). Preseski, honako konposizioa duten gelak prestatu dira: 1) 0,2 $\mathrm{MgO}: 1 \mathrm{P}_{2} \mathrm{O}_{5}: 0,9 \mathrm{Al}_{2} \mathrm{O}_{3}: 1 \mathrm{EBA}$ : 0,012 PY: 0,012 AC: $300 \mathrm{H}_{2} \mathrm{O}$; eta 2) 0,1 MgO: $1 \mathrm{P}_{2} \mathrm{O}_{5}: 0,95 \mathrm{Al}_{2} \mathrm{O}_{3}$ : 1 EBA: 0,008 LDS 722: $300 \mathrm{H}_{2} \mathrm{O}$. Konposizioan antzematen diren moldaketa txikiak koloratzaileen presentzian ere MgAPO-11 fase purua lortzeko gauzatu dira. Labean $180^{\circ} \mathrm{C}$-ra (AC eta PY duen gelaren kasuan) edo $195{ }^{\circ} \mathrm{C}$-ra (LDS 722dun gelaren kasuan) 24 orduz egon ostean, lortzen diren materialak filtrazioz berreskuratzen dira, eta ur destilatuarekin eta etanolarekin ondo garbitu eta gero, lehortzen uzten da. Lagin bakoitzaren sintesirako erabili diren baldintzak 1. taulan laburbildu dira.
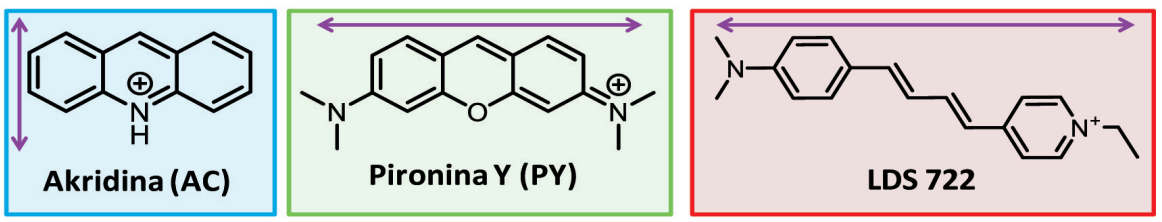

3. irudia. Lan honetan erabilitako koloratzaileen egitura molekularrak. Geziek koloratzaile bakoitzaren trantsizio-momentu dipolarraren norabidea adierazten dute. 
1. taula. Laginak lortzeko prestatutako sintesi-nahasteen konposizioa eta sintesian erabilitako tenperatura eta denbora.

\begin{tabular}{ccccccccccc}
\hline Lagina & $\mathrm{MgO}$ & $\mathrm{P}_{2} \mathrm{O}_{5}$ & $\mathrm{Al}_{2} \mathrm{O}_{3}$ & EBA & AC & PY & LDS722 & $\mathrm{H}_{2} \mathrm{O}$ & $\mathrm{T} /{ }^{\circ} \mathrm{C}$ & $\mathrm{t} /$ ordu \\
\hline MgAPO-11 /AC-PY & 0,20 & 1,00 & 0,90 & 1,00 & 0,012 & 0,012 & - & 300 & 180 & 24 \\
\hline $\mathrm{MgAPO}-11 / \mathrm{LDS} 722$ & 0,10 & 1,00 & 0,95 & 1,00 & - & - & 0,008 & 300 & 195 & 24 \\
\hline
\end{tabular}

\section{EMAITZAK ETA EZTABAIDA}

\subsection{MgAPO-11/AC-PY material hibridoa}

AC eta PY koloratzaile fluoreszenteak batera MgAPO-11 euskarri ezorganikoan kapsulatzean oso lerrokaturik aurkitzea espero da anfitrioiaren kanalen topologia berezia eta neurri estuak direla eta. Horrela, koloratzaileek euren ardatz molekular luzea kanalen c ardatzarekiko paralelo izango dute, eta erantzun anisotropoa erakutsiko dute argi linealki polarizatuaren aurrean. Gainera, koloratzaile bakoitzak bere trantsizio-momentu dipolarra bestearekiko perpendikularra duenez, ACak ardatz molekular motzaren norabidean eta PYak ardatz molekular luzearen norabidean (3. irudia), erantzun hori osagarria izango da, eta PYaren fluoreszentzia berdea ikusiko da polarizatzailea kanalekiko paralelo kokatzean, eta ACaren emisio urdina kanalekiko modu perpendikularrean kokatzen bada.

Dena den, igorpenaren kolore-aldaketa hori ikusteko argi ultramorearekin kitzikatuz gero, bi fluoroforoen artean FRET energia-transferentzia gertatu behar da (Föster Resonance Energy Transfer), non AC elektroiemailea den eta PY elektroi-hartzailea, ezinbestekoa izanik emailearen emisio-banda hartzailearen absortzio-bandarekin gainezartzea. FRET energia-transferentzia hau kromoforoen dipoloen artean eta distantzia luze samarretan (10-100 $⿱$ ) gertatzen den elkarrekintzaren ondorioa da. Egoera kitzikatuan dagoen molekula-emaile batek energia pasatzen dio oinarrizko egoeran dagoen molekula-hartzaile bati. Energia-transferentzia eraginkorra izateko, emaileak etekin kuantiko fluoreszente altua izan behar du, eta gainera, hartzailearekin konparatuz, proportzio askoz altuagoan egon behar da. Nabarmentzekoa da partikula hauetan FRET prozesua gertatzeko egokiak diren baldintzak bete direla. Hala ere, koloratzaileen momentu dipolarren kokapen perpendikularra eragozpena izan beharko litzateke FRET prozesu horren eraginkortasunean, baina, aldameneko kanalen artean energia-transferentzia gertatzeko probabilitatea altua denez, arazo hori konpondu egiten da [23].

Beraz, pauso bakarreko sintesi prozesuan FRET transferentzia gertatzeko baldintzak betetzen dituzten bi koloratzaile gehitzean, zenbait mikrometroko tamainadun partikula angeluzuzenez osatzen den materiala lortzen 
da zeinetan, argi ultramorearekin kitzikatuz gero, igorpen fluoreszentearen kolorearen aldaketa gertatzen den argi polarizatuaren norabidearen arabera (4. irudia). Urdinetik berdera gertatzen den kolore-aldaketa hori efizientea, bat-batekoa, itzulgarria eta errepikakorra da. Gainera, nekearekiko erresistentzia altua erakusten du, kolore-aldaketak ez duelako transformazio kimikorik behar gertatzeko.
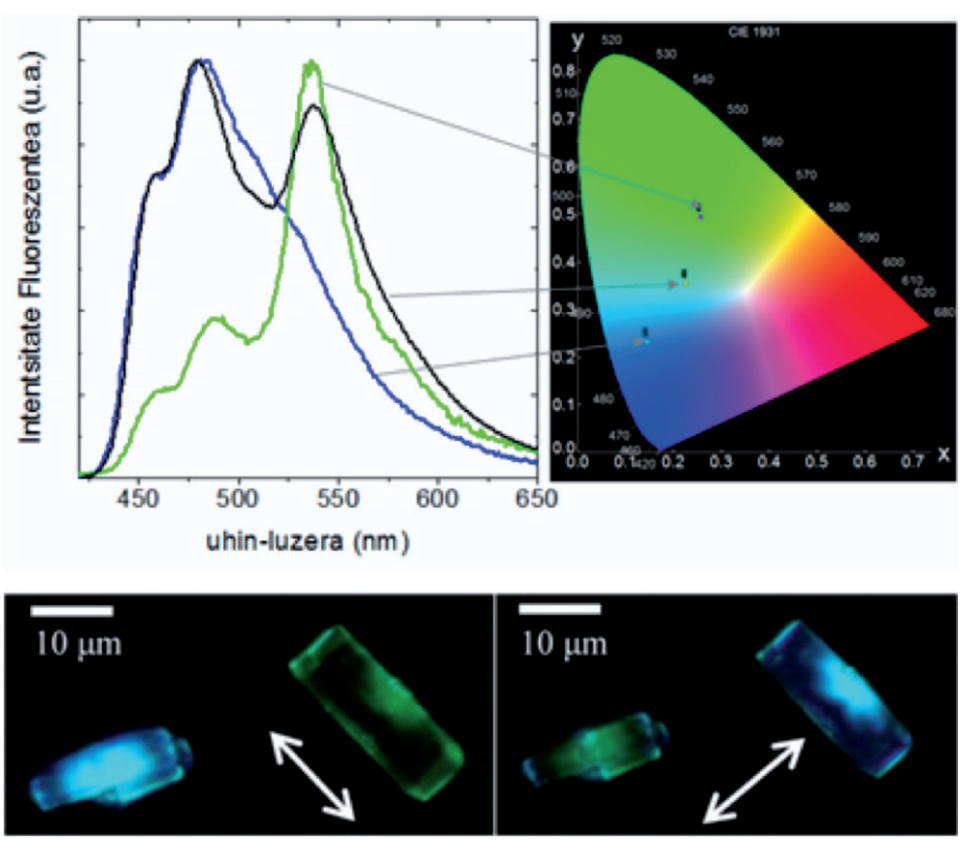

4. irudia. (Ezk.) MgAPO-11/AC-PY partikula bakar baten emisio-espektroak polarizaziorik gabe (beltza), kanalen c ardatzarekiko polarizazio perpendikularrarekin (urdina) eta paraleloarekin (berdea). (Esk.) Emisio-koloreei dagozkien CIE kolore-koordenatuak. (Behean) MgAPO-11/AC-PY partikulen fluoreszentzia-irudiak, detekzioa baino lehen polarizatzaile bat kokatuz jasoak. Geziek polarizatzailearen norabidea adierazten dute.

\subsection{MgAPO-11/LDS722 material hibridoa}

Propietate desberdinak erakusten dituen material bat aurkitu nahian, LDS 722 koloratzailea MgAPO-11 euskarri ez-organikoan kapsulatzea erabaki zen. Koloratzaile honek optika ez-linealaren barne-ezaugarriak azaltzen ditu, push-pull deritzon egitura molekularra duelako, hau da, bere egitura molekularrean talde elektroi-emaile eta elektroi-hartzaileak dituelako [24]. 
Optika ez-linealari buruz hitz egiten dugunean, ingurune desberdinetan gerta daitezkeen eremu elektromagnetikoaren eta materialen arteko elkarrekintzei buruz hitz egiten ari gara. Elkarrekintza horien ondorioz, eremu elektromagnetiko berriak sortzen dira, eta fasea, frekuentzia, anplitudea edo beste propagazio-ezaugarriren bat aldatzen da, hasierako eremu erasotzailearekin konparatuz [25]. Gertakari horiek ez-lineal gisa hartzen dira materialaren erantzunak menpekotasun ez-lineala erakusten duelako eremu erasotzailearen indarrarekiko [26].

Bestalde, LDS 722 koloratzailea oso malgua denez, ez da oso fluoreszentea disoluzioan $\left(\phi_{\mathrm{fl}}: 0,012\right.$, disoluzio urtsuan) [24]. MgAPO-11ren kanal estuetan, ordea, malgutasun hori mugatu egiten da izugarri, eta emaitza gisa etekin kuantiko fluoreszente altuko material hibridoa lortzen da $\left(\phi_{\mathrm{fl}}: 0,55\right)$, espektro elektromagnetikoaren eremu gorrian igortzen duena LDS 722aren ICT emisio-banda (Intramolecular Charge Transfer) dela eta [24]. Gainera, polarizazio-esperimentuen bidez egiaztatu denez, molekulak oso ordenaturik daude partikulen kanaletan zehar (5. irudia), eta intentsitate altueneko emisioa polarizatzailea kanalen c ardatzaren norabidean kokatzean jasotzen da. Argi polarizatuaren norabidea aurrekoarekiko perpendikularki kokatzen denean, ordea, emisioa ia nulua da. Ezaugarri hori kuantifikatzeko fluoreszentziaren erradio dikroikoa edo $D$ deritzon parametroa kalkulatu da eta balio oso altua eskuratu da, 50 ingurukoa, eta berriro ere LDS 722 molekulek partikulen kanaletan zehar ordenamendu maila altua dutela berretsi da, kontutan izanik balio hori 1 inguru izango litzatekeela molekulak zoriz kokatuko balira.

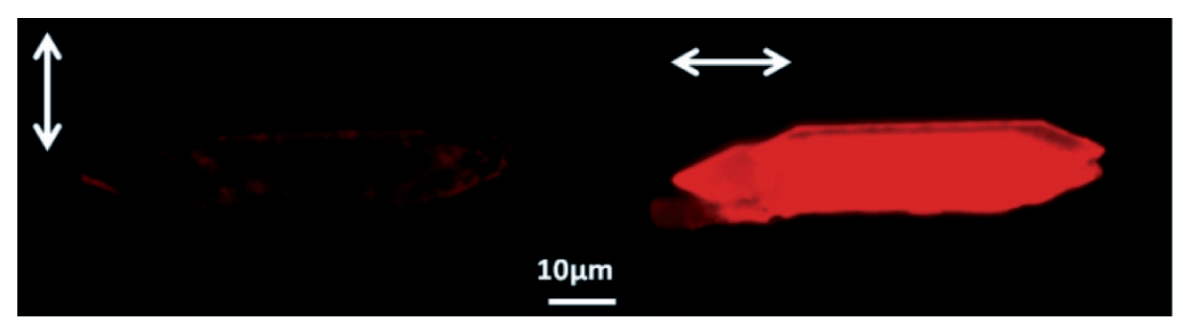

5. irudia. MgAPO-11/LDS 722 partikulen fluoreszentzia-irudi polarizatuak argi berdearekin kitzikatu ostean. Geziek argi polarizatuaren norabidea adierazten dute.

Partikulen ezaugarri optiko ez-linealak aztertzeko femto-segundoetako laser polarizatu batekin kitzikatu ziren $1.024 \mathrm{~nm}$-tan, eta bi fenomeno ikusi ziren: bigarren harmonikoaren sorkuntza (SHG, Second Harmonic Generation, non laser-argi erasotzaileak frekuentzia bikoitza, edo berdina dena, uhin-luzera erdia duen argi-izpi bihurtzen den [26]) eta bi fotoien bidezko kitzikapenaren ondoriozko fluoreszentzia. 6. irudian ikus daiteke aipatutako laserrarekin kitzikatuz lortutako espektroa, non SHGari dagokion 
banda mehar eta intentsua agertzen den 512 nm-tan kokatuta, lauki grisean, eta fotoien bidezko kitzikapenaren ondoriozko fluoreszentzia-banda $650 \mathrm{~nm}$ inguru kokatzen den.

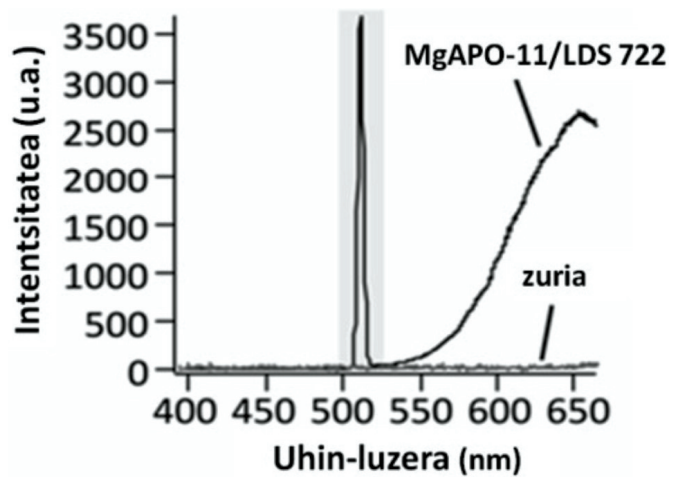

6. irudia. MgAPO-11/LDS 722 materialaren SHG eta bi fotoien bidezko fluoreszentzia-espektroa, 1024 nm-ko uhin-luzeradun laser polarizatuarekin kitzikatuz.

\section{ONDORIOAK}

Frogatu da MgAPO-11 euskarri ez-organikoan koloratzaile fluoreszente desberdinak kapsulatuz material hibrido fluoreszente interesgarriak lor daitezkeela aplikazio optiko ezberdinetan erabilgarriak izan daitezkeenak. Nanokanalak dituen anfitrioi honek koloratzaile-molekulen agregazioa saihesten du barrunbeetan ezartzen zaizkien dimentsio-eragozpenak direla eta. Horri esker koloratzaile karga altuak lor daitezke, behar-beharrezko baldintza materialak aplikazio optikoetarako baliagarriak izateko. Gainera, eragozpen horiek direla medio, fluoroforoei zurruntasuna inposatzen zaie eta euren etekin kuantiko fluoreszentea handitzen da, desaktibazio-bide ez-erradiatzaileak oztopatzen direlako. Bestalde, nanokanaletan lortzen den molekulen lerrokatze maila altua dela eta, argi polarizatuaren aurrean erantzun anisotropoa azaltzen duten material hibridoak lortzen dira. Horrela, material erakargarriak lortu dira bai aplikazio dikroikoetarako bai optika ez-linealeko aplikazioetarako, hala nola, bigarren harmonikoaren sorkuntzarako.

\section{ESKER ONAK}

Lan honek Eusko Jaurlaritza (IT39-10 eta IT912-16) eta Espainiako MINECO (MAT 2012-31127) ikerketa-proiektuen diru-laguntza izan du. 
Halaber, ikerketa UPV/EHUk finantzatutako doktorego aurreko beka bati esker aurrera eraman ahal izan da.

\section{BIBLIOGRAFIA}

[1] KICKELBICK, G. 2007. Hybrid Materials. Synthesis, Characterization and Applications. Wiley-VCH VerlagGmbH\& Co., Weinheim.

[2] PAROLA, S., JULIÁN-LÓPEZ, B. CARLOS, L. D., SANCHEZ, C. 2016. «Optical properties of hybrid organic-inorganic materials and their applications». Adv. Funct. Mater., 26, 6506-6544.

[3] NICOLE, L., LABERTY-ROBERT, C., ROZES, L., SANCHEZ, C. 2014. «Hybrid materials science: a promised land for the integrative design of multifunctional materials». Nanoscale, 6, 6267-6292.

[4] SANCHEZ, C., JULIÁN, B., BELLEVILLE, P., POPALL, M. 2005. «Applications of hybrid organic-inorganic nanocomposites». J. Mater. Chem., 15, 3559-3592.

[5] OUELLET-PLAMONDON, C., ARANDA, P., FAVIER, A., HABERT, G., VAN DAMME, H., RUIZ-HITZKY, E. 2015. «The Maya Blue nanostructured material concept applied to colouringgeopolymers». RSC Adv., 5, 98834-98841.

[6] SÁNCHEZ DEL RÍO, M., MARTINETTO, P., REYES-VALERIO, C., DOORYHÉE, E., SUÁREZ, M. 2006. «SynthesisandacidresistanceofMayaBluepigment». Archaeometry, 48, 115-130.

[7] GARTZIA-RIVERO, L., BAÑUELOS-PRIETO, J., MARTÍNEZ-MARTÍNEZ, V., LÓPEZ-ARBELOA, I. 2012. «Versatile photoactive materials based on zeolite L doped with laser dyes». ChemPlusChem, 77, 61-70.

[8] LI, Z., LUPPI, G., GEIGER, A., JOSEL H.P., DE COLA, L. 2011. «Bioconjugated fluorescent zeolite $\mathrm{L}$ nanocrystals as labels in protein microarrays». Small, 7, 3193-3201.

[9] KIM, H.S., PHAM, T.C.T., YOON, K.B. 2012. «A novelclassofnonlinearopticalmaterialsbased on host-guestcomposites: zeolites as inorganiccrystallinehosts». ChemicalCommunications, 48, 4659-4673.

[10] MARTÍNEZ-MARTÍNEZ, V., GARCÍA, R., GÓMEZ-HORTIGÜELA, L., PÉREZ-PARIENTE, J., LÓPEZ-ARBELOA, I. 2013. «Modulating dye aggregation by incorporation into $1 \mathrm{D}-\mathrm{MgAPO}$ nanochannels». Chemistry $A$ European Journal, 19, 9859-9865.

[11] ARIK, M., ONGANER, Y. 2003. «Molecular excitons of Pyronin B and Pyronin $\mathrm{Y}$ in colloidal silica suspension». ChemicalPhysicsLetters, 375, 126133.

[12] KASHA, M., RAWLS, H., EL-BAYOUMI, M. 1965. «The exciton model in molecular spectroscopy». Pure AppliedChemistry, 11, 371-392.

[13]SCHEBLYKIN, I.G., VARNAVSKY, O.P., VERBOUWE, W., DE BACKER, S., VAN DER AUWERAER, M., VITUKHNOVSKY, A.G. 1998. «Relaxa- 
tion dynamics of excitons in J-aggregates revealing a two-component Davydov splitting». ChemicalPhysicsLetters, 282, 250-256.

[14] HUANG, Y., CHENG, T., LI, F., HUANG, C.H., WANG, S., HUANG, W., GONG, Q. 2002. «Photophysical studies on the mono- and dichromophorichemicyanine dyes III. Ultrafast fluorescence up-conversion in methanol: twisting intramolecular charge transfer and «two-state three-mode» model». Journal of PhysicalChemistry B, 106, 10041-10050.

[15] BAERLOCHER, C., MCCUSKER, L.B., OLSON, D.H. 2007. Atlas ofzeoliteframeworktypes. Elsevier, Amsterdam.

[16] GARTZIA-RIVERO, L., BAÑUELOS-PRIETO, J., LÓPEZ-ARBELOA, I. 2015. «Excitation energy transfer in artificial antennas: from photoactive materials to molecular assemblies». International Reviews in PhysicalChemistry, 34, 515-556.

[17] CUCINOTTA, F., GUENET, A., BIZZARRI, C., MRÓZ, W., BOTTA, C., MILIÁN-MEDINA, B., GIERSCHNER, J., DE COLA, L. 2014. «Energy transfer at the zeolite L boundaries: towards photo- and electroresponsive materials». ChemPlusChem, 79, 45-57.

[18] DEVAUX, A., CALZAFERRI, G., BELSER, P., CAO, P., BRÜHWILER, D., KUNZMANN, A. 2014. «Efficient and robust host-guest antenna composite for light harvesting». ChemistryofMaterials, 26, 6878-6885.

[19] MARTÍNEZ-MARTÍNEZ, V., GARCÍA, R., GÓMEZ-HORTIGÜELA, L., PÉREZ-PARIENTE, J., LÓPEZ-ARBELOA, I. 2012. «Material fotoactivo, método de obtención y uso del material». Espainiako Patentea P201231259.

[20] BIENIOK, A., BRENDEL, U., SERENI, P., MUSSO, M. 2013. «Raman spectroscopy and crystal structure investigation of solvo- and ionothermally prepared microporous metal-aluminophosphates with the laumonite framework structure». ZeitschriftfurKristallographie - CristallineMaterials, 288, 374-381.

[21]LI, D., XU, Y., MA, H., XU, R., WANG, Y., LIU, H., WANG, B., TIAN, Z. 2015. «Ionothermal syntheses of transition-metal-substituted aluminophosphate molecular sieves in the presence of tetraalkylammonium hydroxides». MicroporousandMesoporousMaterials, 210, 125-132.

[22] CHEN, B., HUANG, Y. 2009. «Dry gel conversion synthesis of SAPO- and CoAPO-based molecular sieves by using structurally related preformed AlPO precursors as the starting materials». MicroporousandMesoporousMaterials, 123, 71-77.

[23] CALZAFERRI G. 2012. «Nanochannels: hosts for the supramolecular organization of molecules and complexes». Langmuir, 28, 6216-6231.

[24] CERDÁN, L., COSTELA, A., GARCÍA-MORENO, I., BAÑUELOS-PRIETO, J., LÓPEZ-ARBELOA, I. 2012. «Singular laser behaviour of hemicyanine dyes: unsurpassed efficiency and finely structured spectrum in the near-IR region». Laser PhysicsLetters, 9, 426-433.

[25] WILLIAMS, D. J. 1984. «Organic polymeric and non-polymeric materials with large optical nonlinearities». Angew. Chemie Int. Ed. English, 23, 690-703.

[26] BOYD, R. W. 2008. NonlinearOptics. Academic Press, New York. 